\title{
Effect of ensiling time on fermentation profile and ruminal in vitro starch digestibility in rehydrated corn with or without varied concentrations of wet brewers grains
}

\author{
L. F. Ferraretto, ${ }^{* 1}$ W. I. Silva Filho, ${ }^{*}$ T. Fernandes,${ }^{*} \dagger$ D. H. Kim, ${ }^{*}$ and H. Sultana* \\ *Department of Animal Sciences, University of Florida, Gainesville 32611 \\ †Department of Animal Sciences, Federal University of Lavras, Lavras, MG, Brazil 32700-000
}

\begin{abstract}
The objective of this study was to evaluate the effect of rehydrating and ensiling dry ground corn (DGC) with varying concentrations of wet brewers grain (WBG) on fermentation profile and ruminal in vitro starch digestibility (ivSD; 7-h incubations on dried and 4-mm ground samples). Samples of DGC and WBG were weighed separately and mixed into $100 \%$ WBG (WBG); mixture of DGC and WBG targeting 60 (RC60), 65 (RC65), or $70 \%$ (RC70) of dry matter (DM); and DGC rehydrated with distilled water targeting for $70 \%$ of DM (REH). Samples were ensiled in vacuum-sealed bags and allowed to ferment for 0 , $1,3,7,14$, and $28 \mathrm{~d}$. The experiment consisted of 30 treatments $(5$ mixtures of DGC and WGB $\times 6$ ensiling time points) and 120 mini-silos (4 silos per treatment). All samples were analyzed for fermentation profile and water-soluble carbohydrates. Except for WBG, samples from 0 and $28 \mathrm{~d}$ were analyzed for ivSD. Content of DM was greater for REH (70.0\%), followed by RC70 (69.2\%), RC65 (63.9\%), RC60 (58.4\%), and WBG $(17.5 \%)$ on $\mathrm{d} 0$, with a slight decrease (1 to 2 percentage units) observed for all treatments until $28 \mathrm{~d}$. Measurements of $\mathrm{pH}$ were highest for REH (6.19) and lowest for WBG (4.68) on $0 \mathrm{~d}$, but all other treatments were lower than WBG on 14 and 28 d (3.83 vs. 4.14, on average). Except for WBG, all treatments had a gradual increase in lactic acid concentration from 0 to $28 \mathrm{~d}$. In contrast, butyric acid gradually increased from $0(0.25 \%)$ to $28 \mathrm{~d}(2.16 \%$ of DM) in WBG but not the other treatments. Fermentation patterns were related to water-soluble carbohydrates concentration, which was greater for all treatments except WBG from $0(1.41 \%$ on average vs. $0.38 \%$ of $\mathrm{DM}$, respectively) to $28 \mathrm{~d}(0.37 \%$ on average vs. $0.19 \%$ of DM, respectively).
\end{abstract}

Received December 21, 2017.

Accepted January 23, 2018.

${ }^{1}$ Corresponding author: lferraretto@ufl.edu
Except for RC60, greater ivSD was observed for all treatments on 28 than $0 \mathrm{~d}$, but magnitude of the difference was greater for REH and RC70 (14.5 percentage units on average). Rehydration and ensiling of DGC with WBG resulted in adequate fermentation and enhanced starch digestibility.

Key words: rehydrated corn, wet brewers grain, starch digestibility, ensiling

\section{INTRODUCTION}

Starch is the main energy source in corn grain, the most predominant feed energy source in the United States dairy industry (USDA-ERS, 2016), and comprises approximately 70\% (DM basis) of its nutrient composition. Greater starch digestibility is consistently associated with enhanced milk yield and feed efficiency by lactating dairy cows (Firkins et al., 2001; Ferraretto et al., 2013); thus, improvements in the use of starch by lactating dairy cows is of much interest to dairy farmers and their nutritionists.

Numerous factors influence starch digestibility in corn, including particle size, grain processing, and storage methods (Firkins et al., 2001; Ferraretto et al., 2013). During the ensiling process, zein protein subunits that crosslink starch granules undergo proteolysis (Hoffman et al., 2011), which explains greater ruminal and total-tract starch digestibility when cows are fed high-moisture corn (HMC) in comparison with dry ground corn (DGC; Firkins et al., 2001; Ferraretto et al., 2013). In certain areas (i.e., Brazil), however, the interval for HMC harvesting is narrow, as it coincides with a period of excessive rainfall, which could delay harvesting and, hence, impair fermentation and starch digestibility (Goodrich et al., 1975; Ferraretto et al., 2014). Dry ground corn can be rehydrated to achieve moisture levels that suffice an ensiling process (Rezende et al., 2014). Rehydration and ensiling of DGC was previously reported to enhance ruminal in vitro starch digestibility (ivSD; Ferraretto et al., 2015) and was suggested as an alternative for dairy producers in those 
areas where weather conditions challenge optimal harvest and storage of HMC. A recent study by Arcari et al. (2016) reported enhanced total-tract starch digestibility and milk production when DGC was replaced with rehydrated and ensiled corn in dairy cattle diets.

Although water is typically used in the process of corn rehydration, other products with high-moisture concentration could be used (Rezende et al., 2014). Wet brewers grains (WBG) is a by-product of the brewing process and is widely available in Florida. The main limiting factor for effective use of WBG is its low DM content, which hinders storage and preservation of this residue (Souza et al., 2012). Although ensiling could be an alternative for the storage of WBG (Souza et al., 2012), sugars are removed from the grain during the malting process, which sometimes could result in inadequate amounts of sugars for silage fermentation (Westendorf and Wohlt, 2002). Perhaps WBG could be used as a source of moisture for rehydration of DGC resulting in adequate moisture for ensiling, and thereby result in improved starch digestibility. On the other hand, corn would provide adequate substrate concentration for silage fermentation and improve storage of WBG.

Therefore, our experimental objectives were to evaluate the effect of ensiling time on fermentation profile and ivSD of DGC rehydrated and ensiled without or with 3 concentrations of WBG. We hypothesized that rehydration of DGC with WBG followed by ensiling would result in fermentation patterns similar to rehydration with distilled water. Furthermore, enhanced ivSD would be achieved with rehydration and ensiling regardless of moisture source.

\section{MATERIALS AND METHODS}

Forty kilograms of DGC (finely ground, mean particle size $=649 \mu \mathrm{m}$ ) and $30 \mathrm{~kg}$ of WBG (mean particle size $=687 \mu \mathrm{m}$ ) were obtained from the University of Florida Dairy Research Unit (Gainesville) in September 2016. Samples of DGC and WBG were homogenized, weighed out separately, and thoroughly mixed into $100 \%$ WBG; mixture of DGC and WBG targeting 60 (RC60), 65 (RC65), or 70\% (RC70) of DM; and DGC rehydrated with distilled water targeting for $70 \%$ of DM (REH). For each treatment, mixtures for each silo were independently prepared by hand-mixing, placed in nylon-polyethylene standard barrier vacuum pouches (3.5-mil thickness, $25.4 \times 35.6 \mathrm{~cm}$; Doug Care Equipment Inc., Springville, CA) containing $500 \mathrm{~g}$ of as-fed mixture each, vacuum heat-sealed using an external clamp vacuum machine (Bestvac; distributed by Doug Care Equipment Inc.), and ensiled for 0, 1, 3, 7, 14, and $28 \mathrm{~d}$. Thus, the experiment consisted of 30 treatments
(5 mixtures $\times 6$ ensiling time points) and 120 mini-silos (quadruplicates per treatment). Mini-silos were stored at room temperature (approximately $22^{\circ} \mathrm{C}$ ) in the dark until reaching the targeted ensiling time. After the ensiling time was reached the bags were immediately frozen and stored at $-20^{\circ} \mathrm{C}$ to stop fermentation until being processed for analysis. All samples were frozen for at least $7 \mathrm{~d}$ to ensure protocol similarity among all samples.

A composite sample of each treatment was prepared using 0-d samples for nutrient characterization. Composite samples were sent to Dairyland Laboratories Inc. (Arcadia, WI) and analyzed for ash (method 942.05, AOAC International, 2012), CP (method 990.03, AOAC International, 2012), ether extract (method 920.39, AOAC International, 2012), and NDF determined with heat-stable alpha-amylase and inclusive of residual ash (aNDF; method 2002.04, AOAC International, 2012). Starch was analyzed at University of Florida according to the method of Hall (2015).

Mini-silos were thawed overnight in the refrigerator (approximately $4^{\circ} \mathrm{C}$ ), and representative subsamples were collected from each silo to determine DM content, fermentation profile, and water-soluble carbohydrates (WSC). Samples were dried in duplicate for $48 \mathrm{~h}$ in a forced-air oven set at $60^{\circ} \mathrm{C}$ to determine $\mathrm{DM}$ content. Subsequently, samples were ground to pass a 1-mm screen in a Wiley mill (A. H. Thomas Scientific, Philadelphia, PA). Dried ground samples were analyzed for WSC concentration by the anthrone reaction assay (Ministry of Agriculture, Fisheries, and Food, 1986).

For fermentation profile, $20 \mathrm{~g}$ of wet samples of each mini-silo was diluted into $200 \mathrm{~mL}$ of distilled water and blended in a stomacher (Lab-Blender 400, Tekmar Company, Cincinnati, OH) set at high speed for $30 \mathrm{~s}$, and the suspension was then filtered through 2 layers of cheesecloth. The extract was collected and used immediately for the determination of $\mathrm{pH}$, ammonia- $\mathrm{N}$, and organic acids. The $\mathrm{pH}$ was measured immediately in duplicate using a digital $\mathrm{pH}$ meter (Accumet XL25, Thermo Fisher Scientific Inc., Waltham, MA). Two 20$\mathrm{mL}$ aliquots of extract were separated and treated with $0.2 \mathrm{~mL}$ of $50 \%$ sulfuric acid, centrifuged $(7000 \times g)$ for 15 min at $4^{\circ} \mathrm{C}$, and the supernatant was frozen $\left(-20^{\circ} \mathrm{C}\right)$ for subsequent analysis of organic acids and ammonia$\mathrm{N}$ concentrations. Organic acids concentrations were determined as described by Muck and Dickerson (1988) using HPLC (Merck Hitachi Elite La-Chrome; Hitachi L2400, Tokyo, Japan). Briefly, a Bio-Rad Aminex HPX-87H ion exclusion column $(300 \times 7.8-\mathrm{mm}$ i.d.; Bio-Rad Laboratories, Hercules, CA) was used in an isocratic elution system containing $0.015 M$ sulfuric acid in the mobile phase of HPLC with a UV detector (wavelength $210 \mathrm{~nm}$; L-2400, Hitachi) and a flow rate 
of $0.7 \mathrm{~mL} / \mathrm{min}$ at $46^{\circ} \mathrm{C}$. Ammonia-N was analyzed with a Technicon Auto Analyzer (RFA-300, Alpkem Corporation, Clackamas, OR) adapted from the Noel and Hambleton (1976) method that involved colorimetric N quantification.

Samples of RC60, RC65, RC70, and REH from 0 and $28 \mathrm{~d}$ were dried for $48 \mathrm{~h}$ in a forced-air oven set at $60^{\circ} \mathrm{C}$ and ground to pass a $4-\mathrm{mm}$ screen in a Wiley mill (A. H. Thomas Scientific) to determine ivSD at $7 \mathrm{~h}$. Approximately $0.5 \mathrm{~g}$ was weighed into Ankom F57 filter bags (Ankom Technology, Macedon, NY), in triplicate for each sample, with a pore size of $25 \mu \mathrm{m}$; bags were then placed into $200-\mathrm{mL}$ serum vials. Blank bottles consisting of only a filter bag were also included to allow correction for infiltration of DM into filter bags. Ruminal in vitro digestibility procedures were performed according to the method of Goering and Van Soest (1970) at University of Florida under a protocol approved by the University of Florida, Institute of Food and Agricultural Sciences, Animal Care Research Committee. The ruminal fluid was collected from 3 ruminally cannulated mid-lactation Holstein cows 2 to $3 \mathrm{~h}$ after the morning feed was delivered. Donor cows were fed a TMR containing (DM basis) corn silage $(38.2 \%$ ), alfalfa hay $(4.0 \%)$, and concentrate mixture $(57.8 \%)$. After collection, rumen fluid inoculum was strained through 4 layers of cheesecloth, placed into a prewarmed glasslined thermos, and transported to the laboratory. In the laboratory, rumen fluid was mixed with prewarmed $\left(39^{\circ} \mathrm{C}\right)$ artificial saliva while being continuously gassed with $\mathrm{CO}_{2}$. Each $200-\mathrm{mL}$ bottle was inoculated with 52 $\mathrm{mL}$ of buffered ruminal fluid, gassed with $\mathrm{CO}_{2}$, closed with rubber stoppers, and sealed with aluminum seals. Bottles were incubated for $7 \mathrm{~h}$ at $39^{\circ} \mathrm{C}$ in a forcedair incubator, and the fermentation was terminated by placing the bottles on ice. Filter bags containing residues were rinsed with ambient-temperature distilled water until the effluent was clear and then dried for $48 \mathrm{~h}$ in a forced-air oven set at $60^{\circ} \mathrm{C}$. Dried bags were weighed and residue weight was recorded for further digestibility calculations. Residues were collected from filter bags and analyzed for starch according to the enzymatic-colorimetric method of Hall (2015). Triplicates were composited before starch analysis.

Data were analyzed as a completely randomized design in a $5 \times 6$ factorial arrangement of treatments using PROC GLIMMIX procedure of SAS (version 9.4, SAS Institute Inc., Cary, NC) with the Fixed effects of treatment, ensiling time and their interaction. Means were determined using the least squares means statement and treatment means were compared using the PDIFF option. The ivSD data were analyzed as a completely randomized design in a $4 \times 2$ factorial arrange- ment of treatments using the same model. Statistical significance and trends were declared at $P \leq 0.05$ and $P>0.05$ to $P \leq 0.10$, respectively.

\section{RESULTS AND DISCUSSION}

Nutrient composition of composited 0-d samples are in Table 1. Nutrient composition of WBG was 29.2, $3.8,46.6$, and $12.5 \%$ of $\mathrm{CP}$, ether extract, aNDF, and starch, respectively. These concentrations are similar to those reported by Moriel et al. (2015). Crude protein, ether extract, aNDF, and starch concentrations of treatments containing DGC ranged from 8.1 to 11.3, 3.5 to $4.3,6.2$ to 14.2 , and 57.9 to $66.6 \%$, respectively. This variation was expected and related to different inclusion rates of WBG. As concentration of WBG in the mixture increased, $\mathrm{CP}$, ether extract, and aNDF concentrations numerically increased. In contrast, starch values were numerically reduced. Targeted DM content was achieved for REH (70.0\%, on average) and was $1.62,1.10$, and 0.79 percentage units lower than targeted for the combinations of RC60, RC65, and $\mathrm{RC} 70$, respectively. This is likely related to the slightly lower DM content of WBG than expected (17.5 vs. $20.0 \%$ of as-fed for measured vs. expected, respectively). Expected values were achieved based on measurements of DM performed on 2 previous batches of WBG received by our dairy herd. Content of DM was greater $(P=0.001)$ for $\mathrm{REH}$, followed by RC70, RC65, RC60, and WBG, with a slight decrease (1 to 2 percentage units) observed for all treatments until 28 d (data not presented). This decrease in DM content throughout the ensiling process might be related to the methodology used to quantify the DM content, which excludes the volatile components during oven-drying (Woolford, 1984). Brahmakshatriya and Donker (1971) suggested that the toluene distillation method was the most indicated procedure to evaluate DM of silage because the volume of distillate is corrected for total acids (by titration), ammonia, and ethanol. In contrast, loss of DM will be observed in silage when oven drying is performed (Wilson et al., 1964); however, this minor decrease is not biologically meaningful.

A treatment by time interaction was observed $(P=$ 0.02; Figure 1A) for WSC concentration. Concentration of WSC was lower for WBG than other treatments from 0 (0.38 vs. $1.41 \%$ of DM on average, respectively) to $28 \mathrm{~d}$ ( 0.19 vs. $0.37 \%$ of DM on average, respectively), but greater for REH than mixture treatments on 1, 3, and $7 \mathrm{~d}$ of ensiling. Although it could be argued that the initial WSC concentration for all corn-related treatments in our study were lower than the recommended ideal for growth of lactic acid-producing bacteria in 
silage (2.5\% of DM; Piltz and Kaiser, 2004), our values were similar to those reported for HMC and rehydrated corn by Kung et al. (2014) and Carvalho et al. (2017), respectively. Furthermore, the reduction in $\mathrm{pH}$ (Figure 1B) combined with increased lactic acid concentration (Figure 2A) indicate an adequate fermentation pattern for REH, RC60, RC65, and RC70 but not for WBG, as expected. A treatment by time interaction was observed $(P=0.001$; Figure 1B) for $\mathrm{pH}$; measurements of $\mathrm{pH}$ were greatest for REH (6.19) and lowest for WBG (4.68) on $0 \mathrm{~d}$, but all other treatments were lower than WBG from 3 to $28 \mathrm{~d}$. The reduction of $\mathrm{pH}$ was more evident during the initial $3 \mathrm{~d}$ of fermentation than the longer fermentation days $(7,14$, or $28 \mathrm{~d})$. This result is in contrast to Carvalho et al. (2017), where a slower reduction of $\mathrm{pH}$ during the initial $14 \mathrm{~d}$ of storage of

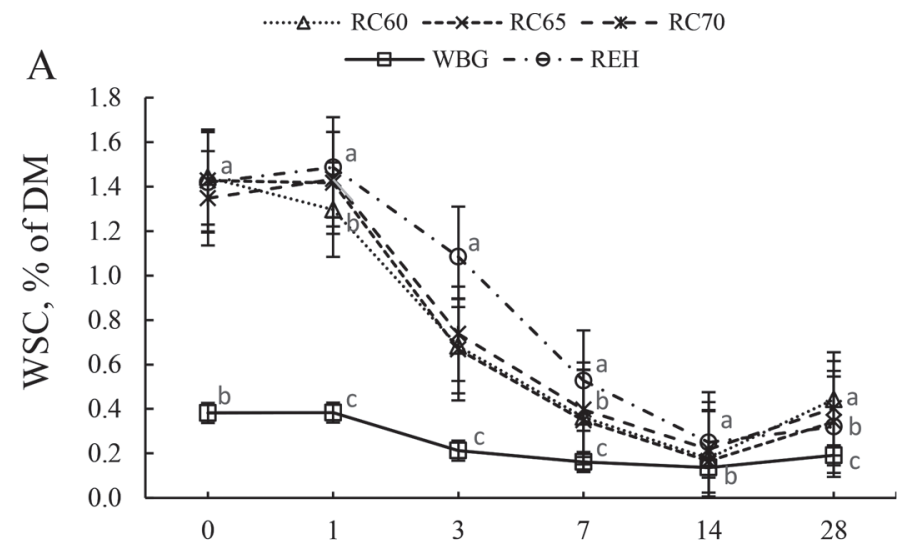

B

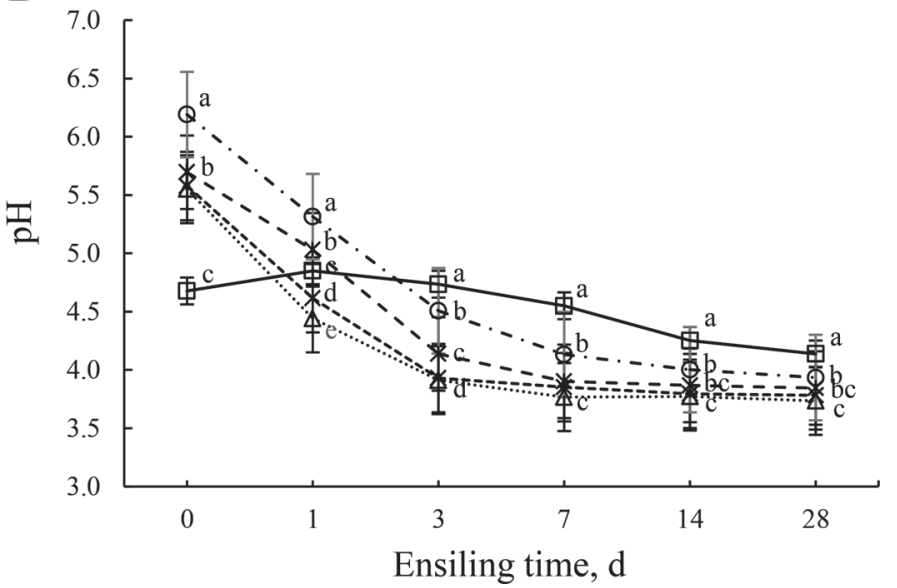

Figure 1. Water-soluble carbohydrates (WSC) concentration (A) and $\mathrm{pH}(\mathrm{B})$ of wet brewers grain (WBG), mixture of dry ground corn and WBG targeting 60 (RC60), 65 (RC65), or 70\% (RC70) of DM, and dry ground corn rehydrated with distilled water targeting for $70 \%$ of DM (REH) ensiled for $0,1,3,7,14$, and 28 d. Means within the same day with different letters $(\mathrm{a}-\mathrm{e}) \operatorname{differ}(P \leq 0.05)$. For panel A, effects of treatment $(P=0.001)$, time $(P=0.001)$, and their interaction $(P$ $=0.001) ; \mathrm{SEM}=0.02$. For panel $\mathrm{B}$, effects of treatment $(P=0.001)$, time $(P=0.001)$, and their interaction $(P=0.001)$; SEM $=0.02$. Error bars indicate SEM.
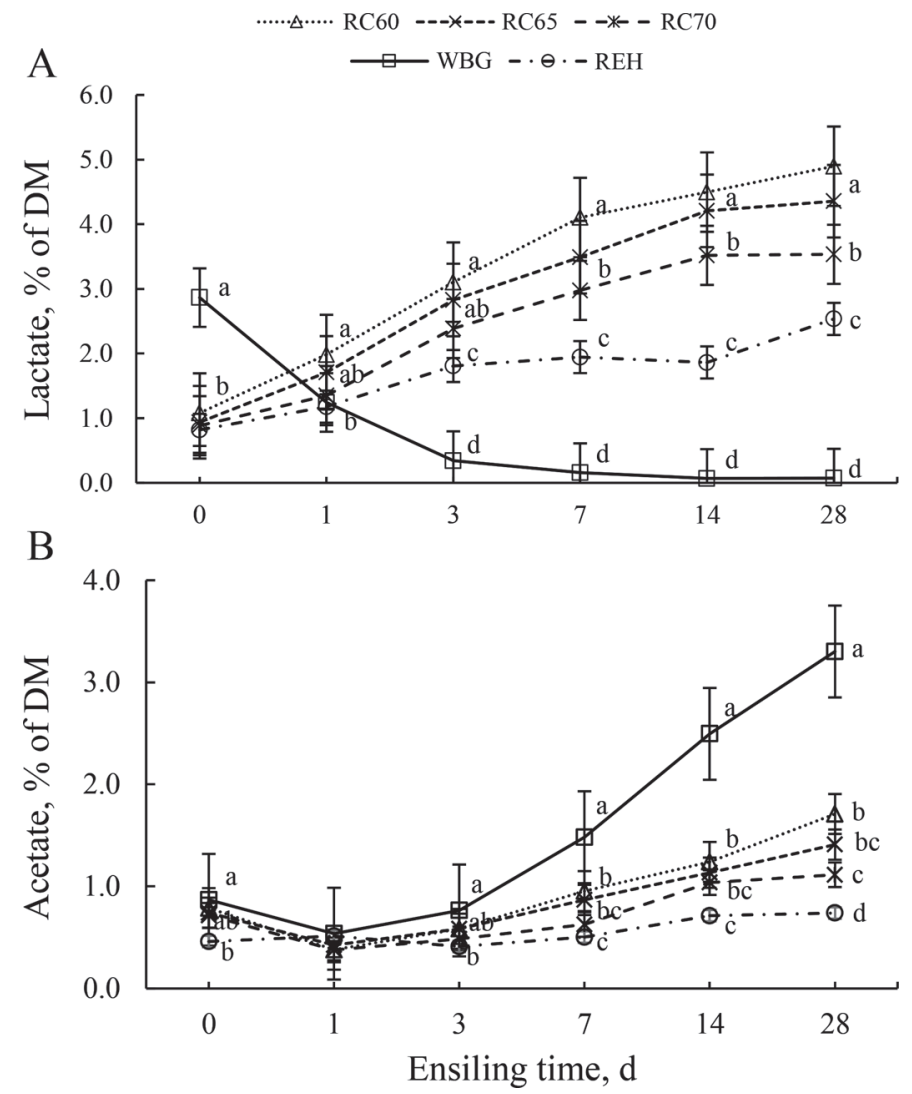

Figure 2. Concentrations of lactic (A) and acetic (B) acids of wet brewers grain (WBG), mixture of dry ground corn and WBG targeting 60 (RC60), 65 (RC65), or 70\% (RC70) of DM, and dry ground corn rehydrated with distilled water targeting for $70 \%$ of DM (REH) ensiled for $0,1,3,7,14$, and $28 \mathrm{~d}$. Means within the same day with different letters $(\mathrm{a}-\mathrm{d})$ differ $(P \leq 0.05)$. For panel A, effects of treatment $(P=0.001)$, time $(P=0.001)$, and their interaction $(P=0.001)$; $\mathrm{SEM}=0.21$. For panel $\mathrm{B}$, effects of treatment $(P=0.001)$, time $(P$ $=0.001)$, and their interaction $(P=0.001) ; \mathrm{SEM}=0.18$. Error bars indicate SEM.

REH was observed. Perhaps the coarser grinding size (3 mm) used by Carvalho et al. (2017) may partially explain this difference.

Table 1. Chemical composition of wet brewers grains (WBG), mixture of dry ground corn and WBG targeting for $60 \%$ (RC60), 65\% (RC65), and $70 \% \mathrm{DM}$ (RC70), and rehydrated dry ground corn (REH) before ensiling

\begin{tabular}{lrrrrr}
\hline Item & WBG & RC60 & RC65 & RC70 & REH \\
\hline DM, \% as fed & 17.5 & 58.4 & 63.9 & 69.2 & 70.0 \\
CP, \% of DM & 29.2 & 11.3 & 11.8 & 10.0 & 8.1 \\
aNDF, \% of DM & 46.6 & 14.2 & 13.0 & 11.6 & 6.2 \\
aNDFom, \% of DM & 45.5 & 13.8 & 12.5 & 11.4 & 5.9 \\
Ether extract, \% of DM & 3.8 & 4.2 & 4.3 & 4.0 & 3.5 \\
Starch, \% of DM & 12.5 & 57.9 & 60.7 & 60.9 & 66.6 \\
NFC, \% of DM & 16.4 & 69.0 & 69.6 & 73.2 & 81.7 \\
Ash, \% of DM & 5.1 & 1.7 & 1.6 & 1.5 & 0.9 \\
\hline
\end{tabular}

${ }^{1}$ aNDF $=$ NDF determined with heat-stable alpha amylase and inclusive of residual ash; aNDFom $=\mathrm{NDF}$ determined with heat-stable alpha amylase and exclusive of residual ash. 
A treatment by time interaction was observed $(P$ $=0.001$; Figure 2A) for lactic acid. Lactic acid was greater for WBG than other treatments on $0 \mathrm{~d}$, but it gradually decreased from 0 to $14 \mathrm{~d}$ ( 2.9 vs. $0.1 \%$ of DM) whereas it increased gradually for all other treatments from 0 to $28 \mathrm{~d}$ ( 0.9 vs. $3.7 \%$ of DM, on average). The continuous increase for rehydrated corn treatments is in agreement with previous literature (Ferraretto et al., 2015; Carvalho et al., 2017). In contrast, Moriel et al. (2016) observed a gradual increase in lactate concentration when WBG was ensiled for 0,14 , and $28 \mathrm{~d}$. Greater lactic acid concentration for RC60, RC65, and $\mathrm{RC} 70$ than REH was observed from 3 to $28 \mathrm{~d}$. Greater lactic acid concentration after $28 \mathrm{~d}$ of ensiling was observed for WBG (6.25\% of DM; Moriel et al., 2016) than REH trials $(1.0 \%$ of DM on average; Ferraretto et al., 2015; Carvalho et al., 2017) and may partially explain this difference. A treatment by time interaction was observed $(P=0.001$; Figure $2 \mathrm{~B})$ for acetic acid concentration. Concentration of acetic acid was greater for WBG than REH on 0 and $3 \mathrm{~d}$ but greater than other treatments from 7 to $28 \mathrm{~d}$ of ensiling. In addition, REH had lower acetic acid concentration than RC60 from 7 to $28 \mathrm{~d}$ and lower than RC65 and RC70 on 28 $\mathrm{d}$; perhaps the limited amount of WSC for WBG led to a shift from lactic toward acetic and butyric acid fermentation. This pattern is typical of some clostridial bacteria that have the ability to convert lactic acid at low $\mathrm{pH}$ values into acetic, propionic, and butyric acids (Pahlow et al., 2003).

A treatment by time interaction was observed $(P$ $=0.001$ ) for propionic acid (Figure 3A). Although all treatments were similar on $0 \mathrm{~d}$, WBG gradually increased throughout the entire ensiling period and, thus, was greater than other treatments from 1 to $28 \mathrm{~d}$ of ensiling. In addition, RC60 had greater propionic acid concentration than REH on 28 d. Moriel et al. (2016) reported an increase in propionic acid concentration for WBG from 0 to $28 \mathrm{~d}$, but the magnitude of the increase was lower than ours (0.8 vs. $3.8 \%$ of DM, respectively, after $28 \mathrm{~d}$ of ensiling). Furthermore, the low propionate concentration in REH is in agreement with previous literature $(0.15$ and $0.14 \%$ of DM after 28 and $30 \mathrm{~d}$ of ensiling, respectively; Ferraretto et al., 2015; Carvalho et al., 2017). Likewise, a treatment by time interaction was observed $(P=0.001)$ for butyric acid (Figure 3B). Butyric acid concentration was similar among all treatments on $0 \mathrm{~d}$, but WBG was greater than other treatments from 1 to $28 \mathrm{~d}$ of ensiling. Butyric acid was not detected in previous trials with WBG (Moriel et al., 2016) and REH (Ferraretto et al., 2015; Carvalho et al., 2017). Many factors could be related to these differences among trials. Malting process within and across breweries vary and, thus, concentrations of DM and WSC are often unpredictable. Low DM and WSC concentrations are well-known factors to elicit elevated butyric acid concentration due to clostridial fermentation (McDonald et al., 1991). With regard to REH, corn epiphytic bacterial population varies and could have contributed to these differences. A treatment by time interaction was observed $(P=0.03)$ for ammonia$\mathrm{N}$ (Figure 4). Ammonia-N was lower for WBG than RC60 on 7 and $14 \mathrm{~d}$ and lower than RC65 on $14 \mathrm{~d}$; however, it was greater than other treatments on $28 \mathrm{~d}$. An increase in ammonia- $\mathrm{N}$ was previously observed for WBG from 0 to $28 \mathrm{~d}$ (Moriel et al., 2016). Perhaps the combination of high moisture but low WSC in WBG led to inadequate fermentation, as evidenced by higher $\mathrm{pH}$, lower concentration of lactic acid, increased ammonia- $\mathrm{N}$ concentration on $28 \mathrm{~d}$, and gradual increase of propionic and butyric acid during storage. Besides the aforementioned low DM and WSC concentrations, clostridial fermentation is also elicited when silage material is stored at elevated temperature, material has high buffering capacity, or if ensiling is delayed (McDonald et al., 1991); however, ensiling was not delayed and room temperature was controlled in the present study. Therefore, impaired fermentation is likely related to WBG low DM and WSC concentrations. Furthermore, most wet by-products have already lost most of their respiration capacity, leaving most of the oxygen remaining in the silo after sealing to be used by undesirable microorganisms (Orosz and Davies, 2015).

Starch concentration was greatest for REH, intermediate for RC65 and RC70, and lowest for RC60 ( $P=$ 0.001 ; data not presented). Average treatment means for starch concentration were 59.8, 62.9, 64.3, and $69.7 \%$ of $\mathrm{DM}$ for RC60, RC65, RC70, and REH, respectively. A treatment by time interaction was observed $(P=$ 0.01) for ivSD (Figure 5). Ensiling for $28 \mathrm{~d}$ increased ivSD by 5.0, 15.5, and 13.9 percentage units for RC65, RC70, and REH, respectively, compared with $0 \mathrm{~d}$, but not for RC60. Ammonia-N gradually increased for these treatments up to $28 \mathrm{~d}$ of ensiling, suggesting that proteolysis of zein proteins and AA occurred during storage (Hoffman et al., 2011). The reason RC60 did not increase ivSD is unclear, as fermentation was more pronounced in RC60 than other treatments. Extent of fermentation is positively related to ivSD in HMC (Ferraretto et al., 2014). Ferraretto et al. (2015) observed a 13.2 percentage unit increase in ivSD for rehydrated and ensiled corn compared with DGC and rehydrated but unensiled corn. Furthermore, greater ruminal in vitro DM digestibility at $7 \mathrm{~h}$ was observed by Carvalho et al. (2017). Our findings suggest that rehydration of DGC with WBG enhances ivSD similarly to REH and may be an option to dairy producers with easy access to WBG. 

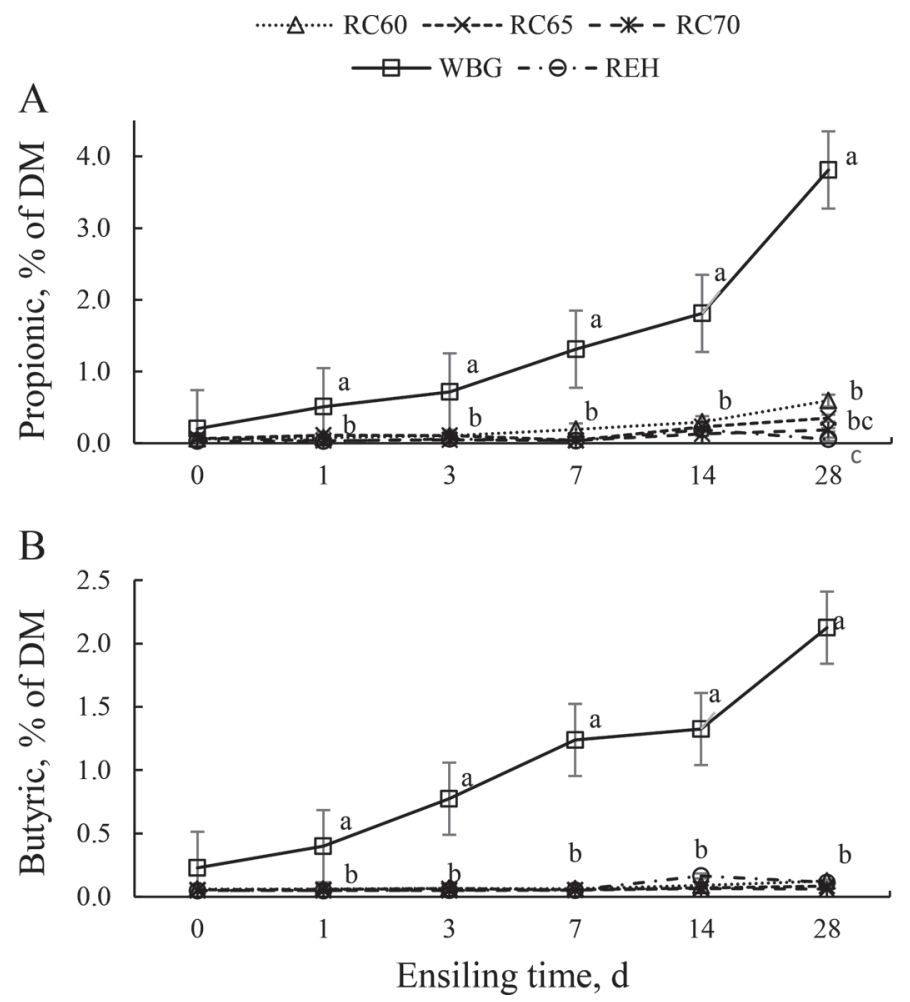

Figure 3. Concentrations of propionic (A) and butyric (B) acids of wet brewers grain (WBG), mixture of dry ground corn and WBG targeting 60 (RC60), 65 (RC65), or 70\% (RC70) of DM, and dry ground corn rehydrated with distilled water targeting for $70 \%$ of DM (REH) ensiled for $0,1,3,7,14$, and 28 d. Means within the same day with different letters $(\mathrm{a}-\mathrm{c})$ differ $(P<0.05)$. For panel A, effects of treatment $(P=0.001)$, time $(P=0.001)$, and their interaction $(P=0.001)$; $\mathrm{SEM}=0.17$. For panel $\mathrm{B}$, effects of treatment $(P=0.001)$, time $(P$ $=0.001)$, and their interaction $(P=0.001) ; \mathrm{SEM}=0.11$. Error bars indicate SEM.

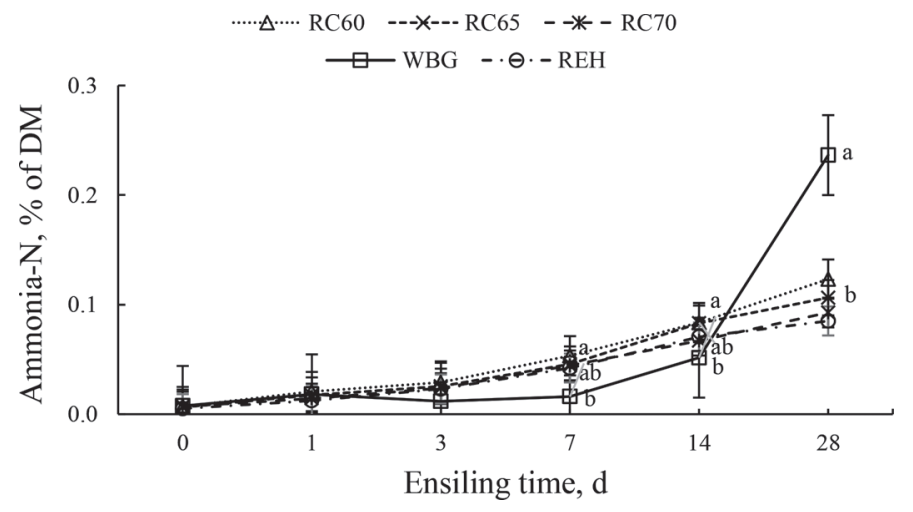

Figure 4. Ammonia-N concentration of wet brewers grain (WBG), mixture of dry ground corn and WBG targeting 60 (RC60), 65 (RC65) or $70 \%$ (RC70) of DM, and dry ground corn rehydrated with distilled water targeting for $70 \%$ of $\mathrm{DM}$ (REH) ensiled for $0,1,3,7,14$, and 28 d. Means within the same day with different letters $(\mathrm{a}, \mathrm{b})$ differ $(P$ $\leq 0.05)$. Effects of treatment $(P=0.03)$, time $(P=0.001)$, and their interaction $(P=0.001)$; SEM $=0.004$. Error bars indicate SEM.

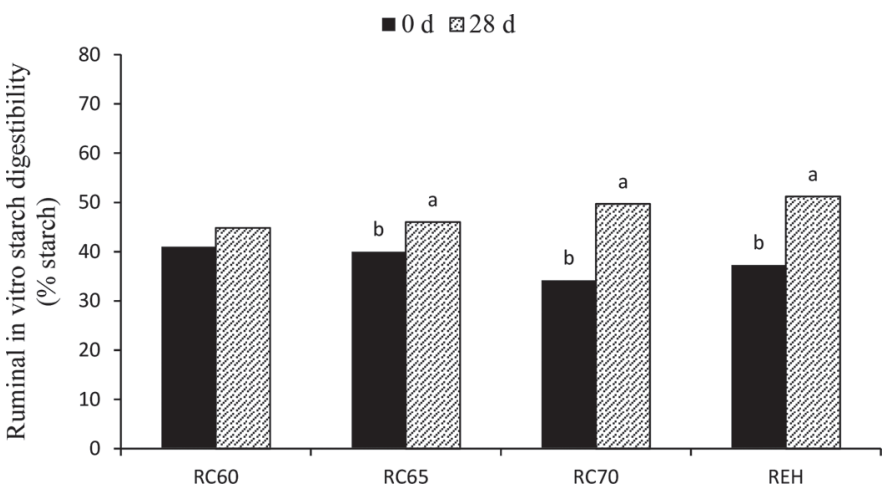

Figure 5. Ruminal in vitro starch digestibility (\% of starch) at 7 $\mathrm{h}$ of mixture of dry ground corn and wet brewers grain targeting 60 (RC60), 65 (RC65), or 70\% (RC70) of DM, and dry ground corn rehydrated with distilled water targeting for $70 \%$ of DM (REH) ensiled for 0 and $28 \mathrm{~d}$. Means within the same treatment with different letters $(\mathrm{a}, \mathrm{b})$ differ $(P \leq 0.05)$. Effects of treatment $(P=0.66)$, time $(P=$ $0.001)$, and their interaction $(P=0.01) ; \mathrm{SEM}=1.3$.

\section{CONCLUSIONS}

Rehydration and ensiling of DGC resulted in adequate fermentation, as evidenced by $\mathrm{pH}$ and lactic acid concentration and greater starch digestibility. These data confirm previous literature findings that ensiling rehydrated corn is a viable alternative for producers in areas where weather conditions compromise optimal harvest and storage of HMC. Furthermore, rehydration and ensiling of DGC with WBG targeting $70 \%$ of DM enhanced starch digestibility to a similar extent as rehydration and ensiling with water. Our results suggest that WBG is a feasible moisture source to rehydrate DGC in areas where its availability and cost are not prohibitive.

\section{ACKNOWLEDGMENTS}

Appreciation is extended to A. T. Adesogan and D. Vyas (Department of Animal Sciences, University of Florida, Gainesville) and their group for the opportunity to use their laboratory equipment during this experiment; and to Todd Pritchard (University of Florida Dairy Research Unit, Gainesville) for providing wet brewers grain and dry ground corn. The authors are also grateful to the Brazilian Federal Agency for PostGraduate Education (CAPES; Brasilia, DF, Brazil) for the financial support to Tatiane Fernandes.

\section{REFERENCES}

AOAC International. 2012. Official Methods of Analysis. 19th ed. AOAC Int., Arlington, VA.

Arcari, M. A., C. M. M. R. Martins, T. Tomazi, J. L. Gonçalves, and M. V. Santos. 2016. Effect of substituting dry corn with rehydrat- 
ed ensiled corn on dairy cow milk yield and nutrient digestibility. Anim. Feed Sci. Technol. 221:167-173.

Brahmakshatriya, R. D., and J. D. Donker. 1971. Five methods for determination of silage dry matter. J. Dairy Sci. 54:1470-1474.

Carvalho, B. F., C. L. S. Avila, T. F. Bernardes, M. N. Pereira, C. Santos, and R. F. Schwan. 2017. Fermentation profile and identification of lactic acid bacteria and yeasts of rehydrated corn kernel silage. J. Appl. Microbiol. 122:589-600.

Ferraretto, L. F., P. M. Crump, and R. D. Shaver. 2013. Effect of cereal grain type and corn grain harvesting and processing methods on intake, digestion and milk production by dairy cows through a meta-analysis. J. Dairy Sci. 96:533-550.

Ferraretto, L. F., S. M. Fredin, and R. D. Shaver. 2015. Influence of ensiling, exogenous protease addition and bacterial inoculation on fermentation profile, nitrogen fractions and ruminal in vitro starch digestibility in rehydrated and high-moisture corn. J. Dairy Sci. 98:7318-7327.

Ferraretto, L. F., K. Taysom, D. Taysom, R. D. Shaver, and P. C. Hoffman. 2014. Relationships between dry matter content, ensiling, ammonia-nitrogen, and ruminal in vitro starch digestibility in high-moisture corn samples. J. Dairy Sci. 97:3221-3227.

Firkins, J. L., M. L. Eastridge, N. R. St-Pierre, and S. M. Noftsger. 2001. Effects of grain variability and processing on starch utilization by lactating cattle. J. Anim. Sci. 79:E218-E238.

Goering, H. K., and P. J. Van Soest. 1970. Forage fiber analyses (Apparatus, reagents, procedures and some applications. Agriculture Handbook No. 379. Agricultural Research Service, USDA, Washington, DC.

Goodrich, R. D., F. M. Byers, and J. C. Meiske. 1975. Influence of moisture content, processing and reconstitution on the fermentation of corn grain. J. Anim. Sci. 41:876-881.

Hall, M. B. 2015. Determination of dietary starch in animal feeds and pet food by an enzymatic-colorimetric method: Collaborative study. J. AOAC Int. 98:397-409.

Hoffman, P. C., N. M. Esser, R. D. Shaver, W. K. Coblentz, M. P. Scott, A. L. Bodnar, R. J. Schmidt, and R. C. Charley. 2011. Influence of ensiling time and inoculation on alteration of the starchprotein matrix in high-moisture corn. J. Dairy Sci. 94:2465-2474.

Kung, L., Jr., M. C. Windle, and N. Walker. 2014. The effect of an exogenous protease on the fermentation and nutritive value of highmoisture corn. J. Dairy Sci. 97:1707-1712.

McDonald, P., A. R. Henderson, and S. J. E. Heron. 1991. The Biochemistry of Silage. 2nd ed. Chalcombe Publ., Marlow, Bucks, UK.

Ministry of Agriculture, Fisheries and Food. 1986. The Analysis of Agricultural Materials. Reference Book 427. Ministry of Agriculture, Fisheries and Food, HMSO, London, UK.
Moriel, P., L. F. A. Artioli, M. H. Poore, and L. F. Ferraretto. 2015. Dry matter loss and nutritional composition of wet brewers grains ensiled with or without covering and with or without soybean hulls and propionic acid. Prof. Anim. Sci. 31:559-567.

Moriel, P., M. B. Piccolo, L. F. A. Artioli, G. S. Santos, M. H. Poore, and L. F. Ferraretto. 2016. Method of propionic acid-based preservative addition and its effects on nutritive value and fermentation characteristics of wet brewers grain ensiled in the summertime. Prof. Anim. Sci. 32:591-597.

Muck, R. E., and J. T. Dickerson. 1988. Storage temperature effects on proteolysis in alfalfa silage. Trans. ASABE 31:1005-1009.

Noel, R. J., and L. G. Hambleton. 1976. Collaborative study of a semi automated method for determination of crude protein in animal feeds. J. Assoc. Off. Anal. Chem. 59:134-140.

Orosz, S., and D. R. Davies. 2015. Short and long term storage of wet by-products fed by ruminants. Pages 200-242 in Proc. XVII Int. Silage Conf., Piracicaba, SP, Brazil. Escola Superior de Agricultura "Luiz de Queiroz," Piracicaba, SP, Brazil.

Pahlow, G., R. E. Muck, F. Driehuis, S. J. W. H. Oude Elferink, and S. F. Spoelstra. 2003. Microbiology of ensiling. Pages 31-93 in Silage Science and Technology. D. R. Buxton, R. E. Muck, and J. H Harrison, ed. Am. Soc. Agron., Madison, WI.

Piltz, J. W., and A. G. Kaiser. 2004. Principles of silage preservation. Pages 25-56 in Successful Silage. 2nd ed. A. G. Kaiser, J. W. Piltz, H. M. Burns, and N. W. Griffiths, ed. Dairy Australia and New South Wales Department of Primary Industries, Orange, NSW, Australia.

Rezende, A. V., C. H. S. Rabelo, R. M. Veiga, L. P. Andrade, C. J. Harter, F. H. S. Rabelo, F. C. Basso, D. A. Nogueira, and R. A. Reis. 2014. Rehydratation of corn grain with acid whey improves the silage quality. Anim. Feed Sci. Technol. 197:213-221.

Souza, L. C., M. A. Zambom, M. S. S. Pozza, M. A. Neres, A. C. Radis, L. Borsatti, D. D. Castagnara, and S. Gundt. 2012. Development of microorganisms during storage of wet brewery waste under aerobic and anaerobic conditions. Rev. Bras. Zootec. 41:188-193.

USDA-ERS. 2016. Overview. United States Department of Agriculture. Accessed Dec. 2, 2016. https://www.ers.usda.gov/topics/ crops/corn.aspx.

Westendorf, M. L., and J. E. Wohlt. 2002. Brewing byproducts: Their use as animal feeds. Vet. Clin. North Am. Food Anim. Pract. 18:233-252.

Wilson, R. F., J. M. A. Tilley, and M. A. Steemers. 1964. Comparison of oven drying and toluene distillation in the determination of the dry-matter content of silage. J. Sci. Food Agric. 15:197-200.

Woolford, M. K. 1984. The Silage Fermentation. 2nd ed. Marcel Dekker, New York, NY. 